\title{
Integration of light and hormone signaling pathways in the regulation of plant shade avoidance syndrome
}

\author{
Yang Liu ${ }^{1}$, Feresheeh Jafari ${ }^{1}$, Haiyang Wang ${ }^{2,3 凶}$ \\ ${ }^{1}$ Biotechnology Research Institute, Chinese Academy of Agricultural Sciences, Beijing 100081, China \\ ${ }^{2}$ State Key Laboratory for Conservation and Utilization of Subtropical Agro-Bioresources, South China Agricultural \\ University, Guangzhou 510642, China \\ 3 Guangdong Laboratory for Lingnan Modern Agriculture, Guangzhou 510642, China
}

Received: 6 January 2021 / Accepted: 24 February 2021 / Published online: 26 April 2021

\begin{abstract}
As sessile organisms, plants are unable to move or escape from their neighboring competitors under high-density planting conditions. Instead, they have evolved the ability to sense changes in light quantity and quality (such as a reduction in photoactive radiation and drop in red/far-red light ratios) and evoke a suite of adaptative responses (such as stem elongation, reduced branching, hyponastic leaf orientation, early flowering and accelerated senescence) collectively termed shade avoidance syndrome (SAS). Over the past few decades, much progress has been made in identifying the various photoreceptor systems and light signaling components implicated in regulating SAS, and in elucidating the underlying molecular mechanisms, based on extensive molecular genetic studies with the model dicotyledonous plant Arabidopsis thaliana. Moreover, an emerging synthesis of the field is that light signaling integrates with the signaling pathways of various phytohormones to coordinately regulate different aspects of SAS. In this review, we present a brief summary of the various cross-talks between light and hormone signaling in regulating SAS. We also present a perspective of manipulating SAS to tailor crop architecture for breeding high-density tolerant crop cultivars.
\end{abstract}

Keywords Arabidopsis, Shade avoidance syndrome (SAS), Light, Hormones, Signaling

\section{INTRODUCTION}

For higher plants, light is arguably one of the most important environmental factors that not only provides energy for photosynthesis but also serves as an informational signal to direct their growth and developmental patterns throughout their life cycle, ranging from seed germination to seedling de-etiolation, vegetative growth, reproductive transition, and seed setting (Lau and Deng 2010). Plants have also evolved an internal time-keeping mechanism, the circadian clock, to help plants to anticipate and synchronize various developmental and physiological activities with the daily

$\bowtie$ Correspondence: whyang@scau.edu.cn (H. Wang) diurnal light/dark cycle generated by the rotation of the earth around the sun, thus increasing plant fitness (Dodd et al. 2005). The plasticity of plants to environmental light changes is inherited in the sophisticated photosensory systems, which through signal transduction and integration, can massively reprogram the transcriptomic activities, leading to adaptive changes in the developmental programs and physiology.

Probably a best manifestation of this plasticity is the shade avoidance response, which is triggered when plants sense competition for light from their neighbors. Under a vegetative canopy, the red (R, 600-700 nm) and blue (B, $400-500 \mathrm{~nm}$ ) spectrum of light is harvested for photosynthesis by upper leaves, whereas farred (FR, 700-800 $\mathrm{nm}$ ) light is transmitted or reflected, 
resulting in a reduction of photoactive radiation (PAR) and reduced R/FR ratios. Plants use a battery of photoreceptors to sense such changes in light quality and quantity, and evoke a suite of adaptive responses collectively termed shade avoidance syndrome (SAS), including stem elongation, reduced branching, hyponastic leaf orientation, early flowering and accelerated senescence (Fig. 1) (Casal 2013; Franklin 2008). These responses are believed to improve individual plant performance and fitness in a crowded plant population, allowing them to finish the life cycle before the canopy getting too dense (Schmitt1997). In addition, shade also redirects more carbon resources to growth at the expense of defense, rendering plants more susceptible to pathogen attack (Ballaré 2014). As SAS is a major limiting factor for high-density planting in agricultural practice, it is expected that a better understanding of the molecular mechanisms governing SAS should provide meaningful approaches and target genes for breeding shade-tolerant crop cultivars through manipulating SAS.

\section{LIGHT REGULATION OF SAS IN ARABIDOPSIS}

\section{Photoreceptors that mediate SAS}

Plants use a set of photoreceptor proteins to monitor the changes in light quantity and quality, including phytochromes (phys), cryptochromes (crys), and UV RESISTANCE LOCUS 8 (UVR8). Under shade conditions, changes in R/FR ratios are perceived by phytochromes which exist in two photoreversible forms: the inactive red light-absorbing (Pr) form and the active far-red light-absorbing (Pfr) form. Upon R light absorption, the Pr form is converted to the Pfr form and translocate into the nucleus to activate light-responsive gene expression (Wang and Wang 2015). The Pfr form of phytochromes can switch back to the Pr form upon FR irradiation or through dark reversion (Whitelam et al. 1998). In the model species Arabidopsis thaliana, there are five phytochrome receptors (phyA-phyE). Of these, phyB is the predominant phytochrome that suppresses shade avoidance, as the mutant deficient in phyB displays a

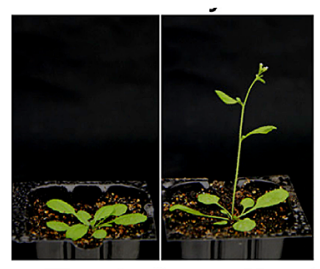

Flowering

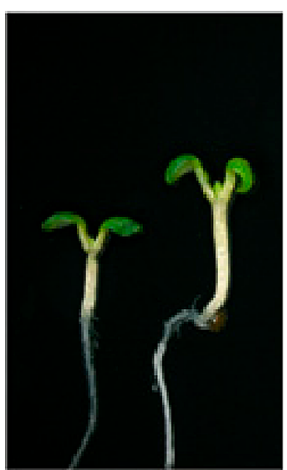

Hypocotyl elongation

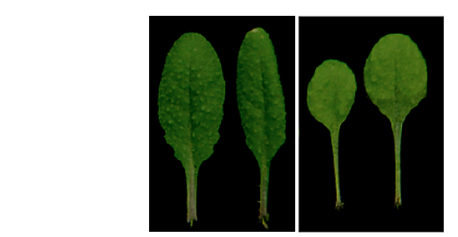

Petiole growth
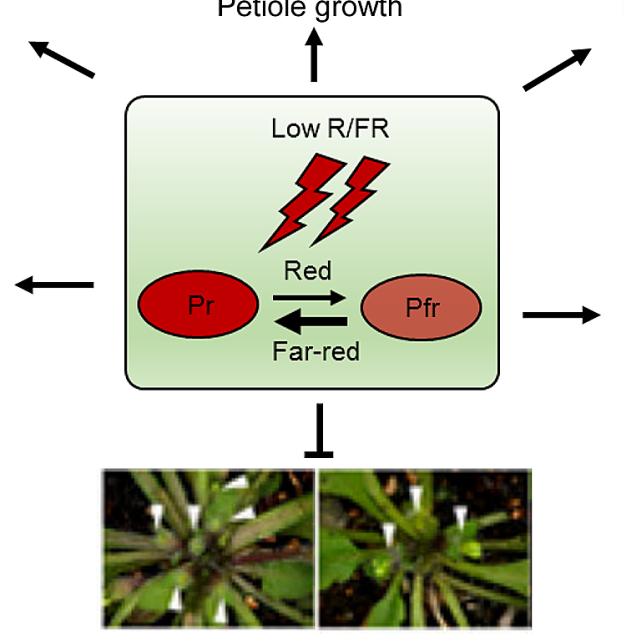

Branching

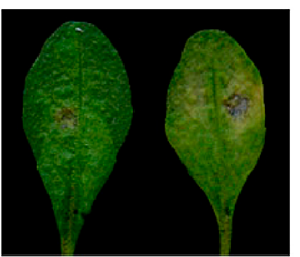

Pathogen infection

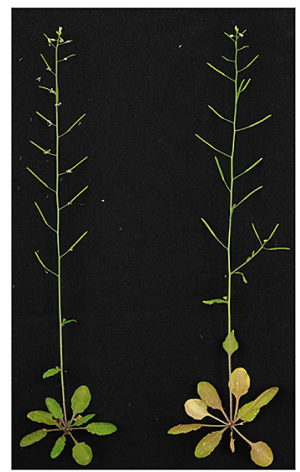

Senescence

Fig. 1 Overview of shade avoidance syndrome. Low R/FR light quality caused by the proximity of competitors induces shade avoidance syndrome. Multiple physiological events, such as accelerated elongation of hypocotyl and petiole, reduced branching, early flowering, precocious senescence and attenuated defense response, are triggered by shade. The wild-type Arabidopsis plant shown on the left is grown under normal white light conditions, while the plants shown on the right is grown under low R/FR ratio conditions. Arrows indicate positive regulation, while bars indicate negative regulation. White arrowheads indicate the short rosette branches. Pictures are adopted from Xie et al. 2017; Liu et al. 2019; Xie et al. 2020a, and 2020b. 
constitutive shade avoidance phenotype (Franklin 2008). In addition, phyD and phyE play additional roles in suppressing shade avoidance in response to reduced R/FR ratios (Franklin et al. 2003). Interestingly, it has been shown that phyA can antagonize SAS induced by phyB inactivation under deep canopy conditions, thus preventing excess SAS (Martínez-García et al. 2014).

In Arabidopsis, there are two cryptochromes, CRY1 and CRY2, that predominantly regulate blue/UV-A-light mediated photomorphogenesis and flowering time, respectively (Ahmad and Cashmore 1993; Guo et al. 1998). They are photolyase-like proteins existing as physiologically inactive monomers in the dark; blue light irradiation leads to homo-oligomerization of CRYs and altered interactions with various cryptochrome-interacting proteins to transduce the blue light signal (Wang and Lin 2020). Under shade conditions, the drop in B light attenuates CRYs-mediated signaling process and evokes SAS through modulating hormone actions (Keller et al. 2011; Keuskamp et al. 2011; Pedmale et al. 2016). UVR8 acts as the photoreceptor for ultraviolet-B (UV-B, 280-315 $\mathrm{nm}$ ) and it exists in an inactive dimeric form in cytoplasm. In response to UV-B exposure, it rapidly monomerizes and translocates into the nucleus to initiate the signal transduction process (Kaiserli and Jenkins 2007; Rizzini et al. 2011). Recent studies showed that repression of shade avoidance by UV-B is UVR8-dependent (Hayes et al. 2014).

\section{Light signaling components that mediate SAS}

The mechanisms of phyB-mediated suppression of hypocotyl/stem elongation have been well elucidated now. It has been shown that active phyB are translocated into the nucleus, where they act to represses SAS via inhibiting the activities of a group of positive regulators of SAS, named PHYTOCHROME INTERACTING FACTORS (PIFs), including PIF3, PIF4 and PIF5 and PIF7 (Lorrain et al. 2008; Xie et al. 2017). The association of active phyB with PIFs triggers the phosphorylation of PIF3, PIF4 and PIF5, leading to their proteasome-mediated degradation (Al-Sady et al. 2006; Shen et al. 2007). Under shade conditions, phyB inactivation by low R/FR light stabilizes PIF3/4/5 and allows them to bind and activate downstream targets, mostly auxin biosynthetic genes and cell wall-associated genes involved in promoting stem elongation (Fig. 2). For PIF7, shade promotes nuclear accumulation of the dephosphorylated form of PIF7, which acts to activate downstream auxin biosynthetic genes to promote SAS (Huang et al. 2018; Leivar et al. 2008; Li et al. 2012).

Moreover, PIF activity is also regulated by a group of SAS negative regulators, such as LONG HYPOCOTYL IN

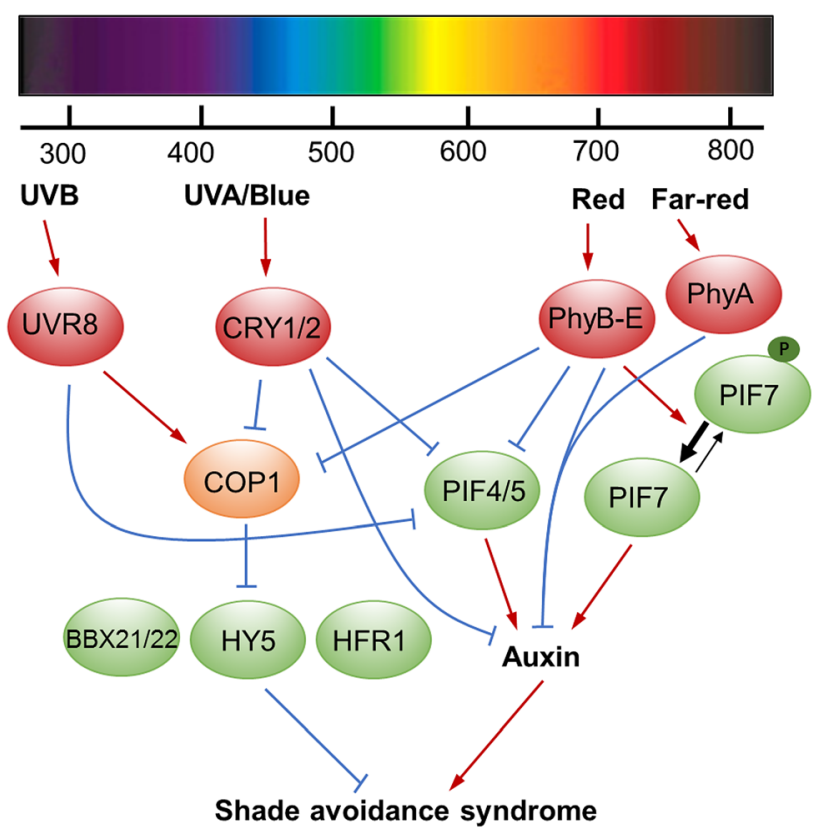

Fig. 2 Perception of shade light by photoreceptor signaling network. Photoreceptors detect different light wavelengths and transduce the signal to downstream signaling factors. Low R/FR or low blue light causes inactivation of phytochromes (mainly phyB) or CRYs, respectively, leading to accumulation of PIF4, PIF5 and dephosphorylated PIF7 proteins and activation of auxinrelated genes, and thus shade avoidance syndrome. UV-B also represses SAS also through reducing PIF4/5 activity. The light signaling repressor COP1 promotes SAS through degradation of SAS repressors, such as BBX21/22, HY5 and HFR1. Red arrows indicate activation, blue bars indicate inhibition

FAR RED 1 (HFR1), PHYTOCHROME RAPIDLY REGULATED1 (PAR1) and PAR2 (Bou-torrent et al. 2011; Buti et al. 2020; Hao et al. 2012). HFR1 and PARs are atypical HLH proteins that do not directly bind DNA, instead they interact with the DNA-binding domain of PIFs, thereby repressing the transcriptional activities of PIFs (Galstyan et al. 2011; Hornitschek et al. 2009). Interestingly, these negative regulators of SAS are rapidly promoted by low R/FR and transcriptionally activated by PIFs, suggesting that these negative regulators of PIFs could serve as a brake mechanism to fine-tune SAS. Additional PIF direct targets include the homeodomainleucine zipper transcription factor ARABIDOPSIS THALIANA HOMEOBOX PROTEIN2 (ATHB2) and PIFLIKE1 (PIL1), which are also promoted by low R/FR to fine-tune shade avoidance responses (Hornitschek et al. 2012; Kunihiro et al. 2011). Recently, FAR-RED ELONGATED HYPOCOTYL3 (FHY3) and FAR-RED IMPAIRED RESPONSE1 (FAR1), which encode a pair of transposasederived transcription factors essential for phyA-mediated FR light signaling in Arabidopsis (Lin et al. 2007), were shown to interact with PIF3/5, and act as negative regulators of SAS as well (Liu et al. 2019, 2020). FHY3 
and FAR1 can also directly activate the expression of PAR1 and PAR2 to downregulate SAS (Liu et al. 2019).

In addition, several studies have also implicated CONSTITUTIVE PHOTOMORPHOGENIC1 (COP1), ELONGATED HYPOCOTYL5 (HY5) and members of the B-box (BBX) family proteins in SAS regulation. COP1 encodes an E3 ubiquitin ligase that is accumulated in the nucleus in darkness, where it acts as a central repressor of photomorphogenesis through targeted degradation of transcription activators such as HY5, HFR1 and LONG AFTER FAR-RED LIGHT1 (LAF1). Light triggers the migration of COP1 into the cytosol, thus abolishing its repressive effect on photomorphogenesis (Osterlund et al. 2000; Seo et al. 2003; Yang et al. 2005). Typical SAS requires COP1, as SAS and SAS-associated gene expression is suppressed in cop1 mutants (RoigVillanova et al. 2006). Interestingly, it was shown that natural or simulated shade conditions can induce rapid nuclear re-accumulation of COP1, and that afternoon shade is more effective than morning shade in inducing nuclear re-accumulation of COP1, implicating a possible role of COP1 in fine-tuning SAS in response to the fluctuating light environments (Pacín et al. 2013). Recently, COP1 was shown to promote the stabilization of PIF3 and PIF5 through repressing BIN2-mediated phosphorylation and degradation (Ling et al. 2017; Pham et al. 2018). Although HY5 does not appear to be involved in the control of hypocotyl growth in response to shade, it was shown to play a critical role in suppressing sunfleck-mediated shade-avoidance response (Roig-Villanova et al. 2006; Sellaro et al. 2011). Notably, the B-box Domain Protein 21 (BBX21) and BBX22 were shown to negatively regulate SAS, whereas BBX24 and BBX25 were shown to promote shade avoidance response (Crocco et al. 2010, 2015), although these BBX proteins are all targeted for $26 \mathrm{~S}$ proteasome-mediated degradation in a COP1-dependent manner (Chang et al. 2011; Gangappa et al. 2013; Indorf et al. 2007; Xu et al. 2016). The detailed molecular mechanisms underlying the differential roles of these BBX proteins and their regulation await further studies.

Interestingly, recent studies showed that both low blue light (LBL)- and UV-B mediated SAS also acts through modulating PIF4 and PIF5 activity (Fig. 2). It was shown that PIF4 and PIF5 are also cryptochromeinteracting proteins and that PIF4, PIF5, and CRY2 bind to common chromatin regions of target genes (Pedmale et al. 2016). In addition, a role of phyB in suppressing LBL-mediated SAS has also been observed (Pedmale et al. 2016). Moreover, LBL can potentiate low R/FRinduced SAS by increasing PIF5 abundance and attenuating low R/FR-induced gene expression of negative regulators (such as HFR1) (de Wit et al. 2016). In addition, it has been shown that B light-activated CRY1 and CRY2 associate with the COP1/SPA1 complex and suppress their ubiquitin ligase activity, thus inhibiting hypocotyl elongation (Liu et al. 2011). Thus, cryptochrome signaling and phytochrome signaling are integrated to modulate plants' response to a changing environment.

Similarly, it has been shown that UVR8-mediated suppression of hypocotyl elongation also requires degradation of PIF4 and PIF5 (Tavridou et al. 2020a). On the other hand, HFR1 is stabilized under UV-B in a UVR8-dependent manner, which functions in part redundantly with PIL1 to suppress shade-induced gene expression (Tavridou et al. 2020b). In addition, it was recently shown that UV-B induced nuclear accumulation of UVR8 monomeric protein is dependent on COP1 (Yin et al. 2016) and that COP1 interacts with PIF5 to stabilize PIF5 in light-grown plants. Exposure to UV-B promotes the association of UVR8 with COP1, thus disrupting the stabilization of PIF5 by COP1, leads to rapid degradation of PIF5 via the ubiquitin-proteasome system and suppression of SAS (Sharma et al. 2019).

\section{INTEGRATION OF LIGHT WITH VARIOUS HORMONES IN REGULATING DIFFERENT ASPECTS OF SAS}

It is worth noting that our mechanistic understanding of the signaling pathways of SAS is mostly derived from studies focused on the elongation process in Arabidopsis. Actually, high-density planting elicits diverse responses beyond stem and petiole elongation, including reduced branching, acceleration of flowering time, attenuated defense response and early senescence. These SAS-related physiological responses are regulated by the combined action of light together with a number of plant hormones, including gibberellin (GAs), auxin, brassinosteroids (BR), jasmonic acid (JA), strigolactone (SL), abscisic acid (ABA) and ethylene. Here we describe recent advances on the regulatory mechanisms of various shade avoidance responses by the integration of light with various hormone signaling pathways.

\section{Light signaling cross-talks with Auxin/BR/GAs signaling to regulate stem elongation}

Auxin plays a major role in shade-induced elongation of hypocotyl, stem and petiole. Under low R/FR conditions, PIF4 and PIF5 are stabilized, while PIF7 is dephosphorylated, and they act together to regulate auxin activity at levels of biosynthesis, transport and signaling (Hornitschek et al. 2012; Iglesias et al. 2018; Li et al. 2012; Sun et al. 2012) (Fig. 3). Consistently, the pif4 pif5 


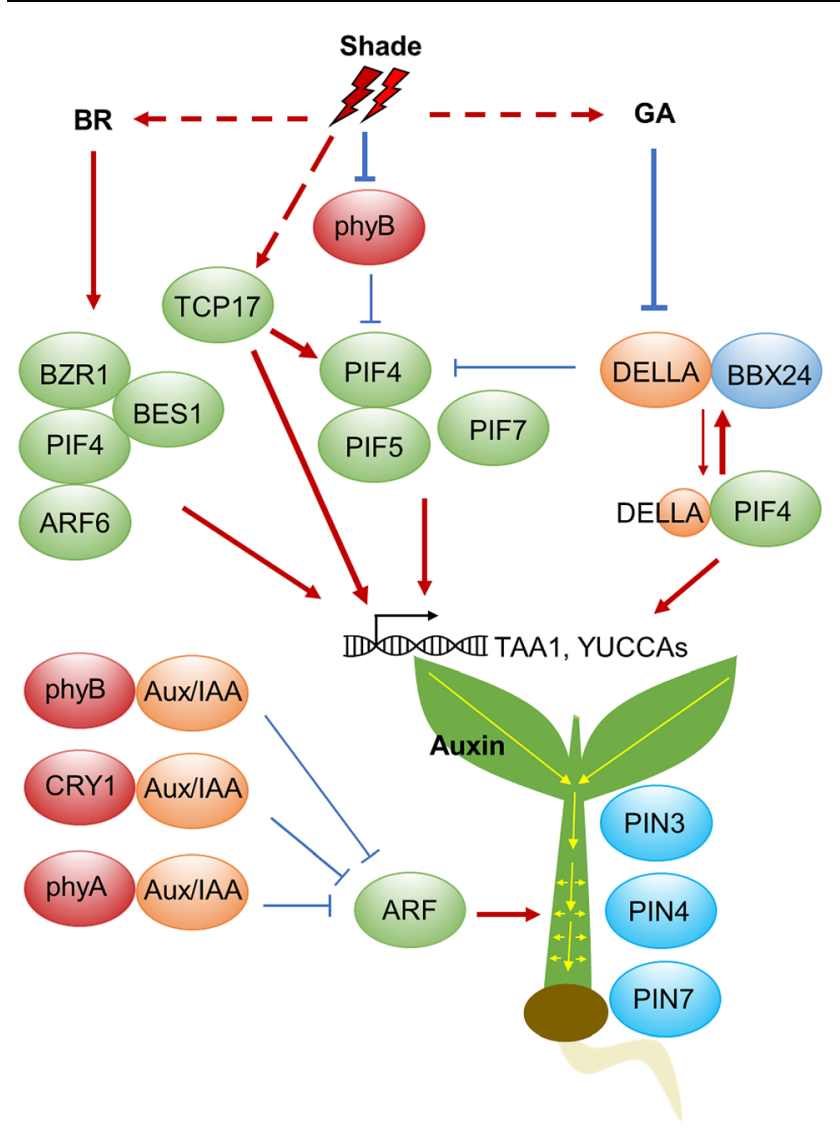

Fig. 3 Integration of auxin, BR and GA in shade-mediated stem elongation. Upon shade light, transcription factors PIF4, PIF5 and PIF7 are activated, and GA and BR levels are increased. As a result, BZR1 and BES1 are activated and form a complex with PIF4 and ARF6. DELLA is inhibited through GA-mediated degradation, thus PIF4 is released from repression by DELLA. The transcription regulator BBX24 physically interacts with DELLA and prevents it from interacting with and repressing PIF4. Consequently, auxin biosynthetic genes TAA1 and YUCCA are transcriptionally activated. Low R/FR induces synthesis of auxin in the cotyledons, which is subsequently transported to the hypocotyl via auxin efflux-associated protein PIN-FORMED 3 (PIN3), 4 and 7 to promote growth. Due to direct interaction between photoreceptors and several Aux/IAA proteins, auxin signaling is enhanced as auxin response factors (ARFs) are relieved from Aux/IAA repression. Arrows indicate positive regulation, while bars indicate negative regulation. Bold arrows and bars indicate the events favoured under shade conditions

mutant and mutants of reduced auxin levels, such as higher order yuc mutants and sav3/wei8/taa1, are defective in low R/FR-induced hypocotyl elongation and other shade avoidance responses (Nozue et al. 2015; Hornitschek et al. 2012). Typically, low R/FR conditions induce auxin synthesis in the cotyledons, which is subsequently transported to the hypocotyl via the auxin efflux-associated protein PIN-FORMED 3 (PIN3), PIN4 and PIN7 to promote hypocotyl growth (Keuskamp et al. 2010; Kohnen et al. 2016; Procko et al. 2014). In particular, shade induces changes in the cellular location of
PIN3, which leads to increased free auxin levels in the hypocotyl epidermal cells (Procko et al. 2016). Auxin sensitivity and responsiveness are also enhanced by low R/FR. It has been reported that photoactivated phyB and CRY1 are able to interact with AUX/IAA proteins, and inhibit the binding of AUX/IAAs with the auxin receptor TIR1, thus protecting AUX/IAAs from auxininduced degradation, resulting in impaired auxin signaling in high R/FR (Xu et al. 2018). Thus, inactivation of phyB and CRY1 by low R/FR and LBL, respectively, could lead to enhanced auxin signaling and SAS. Moreover, it was recently shown that photoactivated CRY1 and phyB can physically interact with ARF6 and ARF8, and repress their DNA-binding activity on downstream target genes, thus inhibiting auxin-induced hypocotyl elongation (Mao et al. 2020). A recent study also showed that a member of TEOSINTE BRANCHED1, CYCLOIDEA, and PCF (TCP) family, TCP17, promotes shade avoidance through upregulating PIF4 level and auxin biosynthesis (Zhou et al. 2018).

While the above studies primarily focused on the early events of SAS, a recent study provided novel insight into SAS under persistent shade when auxin levels have declined to the prestimulation values. It was found that the sustained inactivation of phytochrome B under persistent shade leads to altered PIF4 expression profiling, thus modifying auxin perception and signaling to sustain SAS without enhancing auxin levels (Pucciariello et al. 2018).

GAs is another hormone that promotes stem and petiole growth. Low R/FR condition increases GA level partly through transcriptional upregulation of the GA synthesis genes GA20ox1 and GA200x2 (Hisamatsu et al. 2005). DELLA proteins are a subset of plant-specific GRAS family regulators that repress GA signaling, and they are degraded by the SCF ${ }^{\text {SLY1/GID2 }}$ complex in a GAdependent manner (Davière and Achard 2013). Interestingly, it was shown that DELLA is able to interact with PIFs and suppress their activities (De Lucas et al. 2008; Feng et al. 2008). Low R/FR ratios or phyB inactivation promote DELLA degradation, resulting in relief of PIFs to promote hypocotyl/stem growth (Djakovic-Petrovic et al. 2007; Leone et al. 2014). Moreover, it was shown that the transcriptional regulators BBX24 and BBX25 physically interact with the DELLA protein GAI and prevent it from interacting with and repressing PIF4, thus promoting GA-induced cell elongation (Crocco et al. 2015). In addition, COP1 can directly regulate DELLA protein stability, because DELLA is targeted for degradation by COP1 in response to shade signal (Blanco-Touriñán et al. 2020).

Shade also stimulates stem growth through coordinating brassinosteroids signaling. The BR signaling 
components BR-ENHANCED EXPRESSION (BEE) and BES1-INTERACTING MYC-LIKE (BIM) are positive regulators of SAS (Bou-torrent et al. 2013). Importantly, the central BR signaling regulator BRASSINAZOLE RESISTANT1 (BZR1), together with ARF6 and PIF4, form a regulatory module known as the BAP module, which is activated to coordinate growth in response to multiple growth-regulating signals, such as shade (Bouré et al. 2019; Oh et al. 2014). This BAP module may also include BRI1 EMS SUPPRESSOR1 (BES1), which can interact with PIF4, and thus switching BES1 from a repressor to an activator (Martínez et al. 2018). A recent study showed that PIF4, PIF5 and PIF7 act redundantly to upregulate BR SIGNALING KINASE5 (BSK5) expression in shade conditions, leading to activation of the BES1/PIF4/PIF5 signaling module (Hayes et al. 2019). In addition, BR and GA also act interdependently to promote hypocotyl growth, as the DNA-binding activity of BZR1 is inhibited by DELLA (Bai et al. 2012). Therefore, shade activates auxin, GA and BR signaling pathways to synergistically activate downstream central transcription factors, such as the BAP module, to promote stem growth and other shade avoidance responses.

PHYA is known to play a major role in suppressing SAS under deep shade (Martínez-García et al. 2014), however, the underlying molecular mechanism has remained obscure. Yang et al. (2018) recently showed that the accumulation of PHYA is increased under shade, which releases the repressive auxin/indole-3-acetic acid (AUX/IAA) proteins from $\mathrm{SCF}^{\mathrm{TIR} 1}$-mediated degradation, thus weakening auxin signaling and negatively regulating shade responses. Moreover, it was recently shown that under deep canopy, nulcear accumulation of PHYA is promoted, causing reduced COP1 nuclear speckles and subsequent changes in downstream target genes (PIF4, PIF5 and HY5), and consequently inhibits SAS through modulating BES1/BZR1 and BR signaling (Song et al. 2020).

It is also worth mentioning that reduced R/FR ratios can promote phototropism of de-etiolated seedlings (reorientation of hypocotyl growth) through phyB-controlled auxin biosynthesis, to avoid canopy shade (Goyal et al. 2016). A recent study further showed that persistent LBL promotes seedling phototropism and that this response is also regulated by phyB and the CRY1PIF4 module through modulating auxin signaling in the hypocotyls, thus reinforcing a critical role of the CRY1PIF4 module in regulating different light-mediated responses (Boccaccini et al. 2020).
Light and the miR156/SPL module control SLand $A B A-m e d i a t e d$ regulation of branching

Branching (tillering in cereal crops) is a major component of plant architecture and a critical determinant of crop productivity. Shade suppresses axillary bud outgrowth and thus reducing branching. phyB inactivation or PIF4/PIF5 overexpression leads to branching repression in both high and low R/FR light conditions (Holalu et al. 2020; Reddy and Finlayson 2014; Xie et al. 2017). A major genetic pathway regulating branch outgrowth is the TB1/FC1/BRC1 pathway that represses axillary bud outgrowth in both monocots and dicots (Wang et al. 2019). Recent studies showed that under canopy shade conditions, inactivation of phyB causes elevated BRC1 expression in the axillary buds in a manner dependent on PIF4 and PIF5 (Finlayson et al. 2010; Holalu et al. 2020).

Several studies have shown that the miR156-SQUAMOSA-PROMOTER BINDING PROTEIN-LIKE (SPL) module plays an important role in controlling FC1/BRC1 expression (Jiao et al. 2010; Wang et al. 2015; Xie et al. 2020a). It has been shown that Arabidopsis SPL9/15 and rice OsSPL14 are able to directly bind to the $B R C 1$ and FC1 promoter, respectively, and activate their transcription (Song et al. 2017; Xie et al.2020a). Mechanistically, inactivation of phytochrome $B$ under shade conditions promotes accumulation of PIFs, which directly bind to the promoters of multiple MIR156 genes and repress their expression, resulting in the release of downstream SPL genes to promote SAS (Xie et al. 2017). The upregulation of BRC1 by SPL proteins contributes to reducing branching (Fig. 4). Moreover, it was shown that FHY3 and FAR1 interact with both SPL9 and SPL15 and inhibit their binding to the BRC1 promoter, and that simulated shade conditions downregulate the accumulation of FHY3 and FAR1 proteins, thereby upregulating BRC1 level and suppressing branching (Xie et al. 2020a). Together, these findings suggest that two sets of SAS regulators, FHY3/FAR1 and PIFs, control branching through oppositely modulating SPL activity/expression and thus BRC1 expression.

It is known that tiller bud growth is also repressed by a carotenoid-derived hormone strigolactone. SL represses bud outgrowth and branching through promoting the degradation of a set of central repressor proteins, DWARF 53 (D53) in rice and D53-like SUPPRESSOR OF MORE AXILLARY GROWTH2-LIKE proteins (SMXL6/7/ 8) in Arabidopsis, which relieve their transcriptional inhibitory effect on SPL-activated BRC1/FC1 expression (Song et al. 2017; Wang et al. 2018). Strikingly, at least two SMXLS (SMXL6 and SMXL7) are directly activated by FHY3 and FAR1. Moreover, SMXL6, SMXL7, and SMXL8 


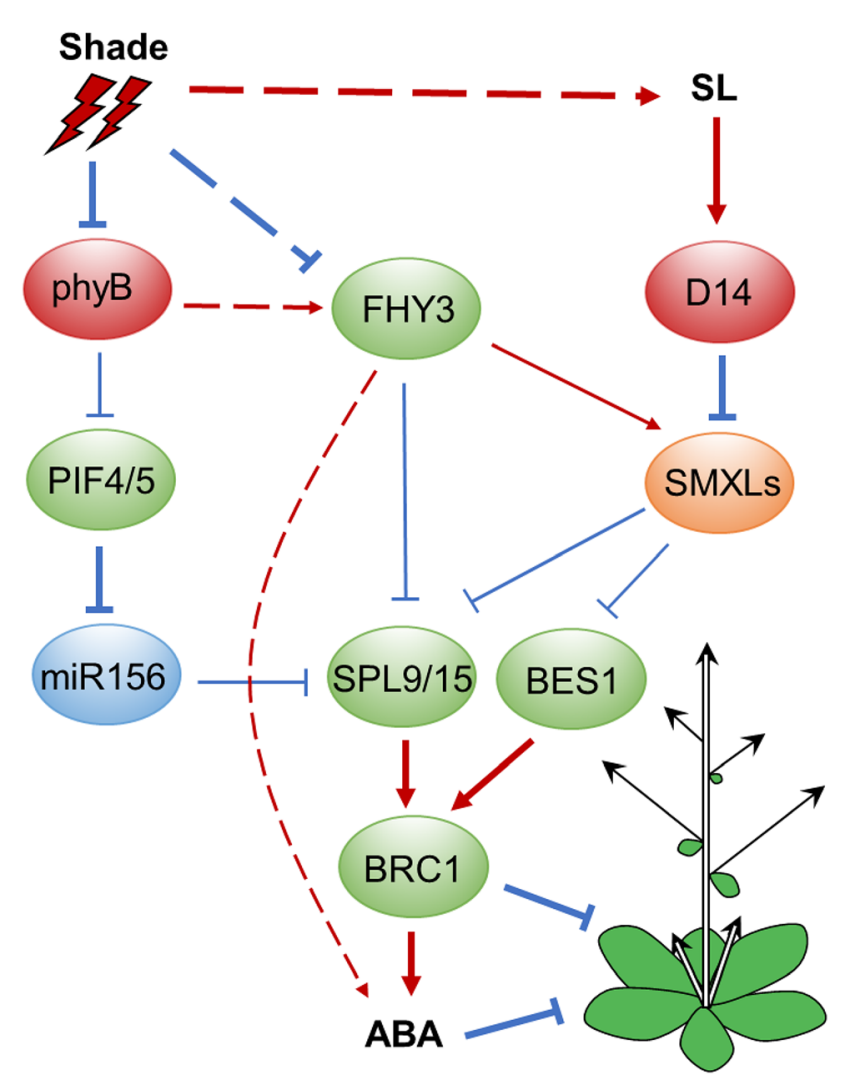

Fig. 4 The crosstalk between SL and ABA in shade-mediated shoot branching. Shade-mediated PIF4/5 activation represses MIR156 expression, thereby releasing its targets SPL9/15 to promote BRC1 expression and repress branching. Shade conditions also downregulate FHY3 protein accumulation, thus reliefing SPL9 and SPL15 from inhibition by FHY3, leads to activation of BRC1 expression. The SL repressor proteins SMXLs are directly up-regulated by FHY3. SMXL proteins can interact with SPL9/15 and BES1, and repress their transcriptional activity on BRC1, thereby regulating branching. ABA acts downstream of $B R C 1$ and FHY3 to regulate branching. Arrows indicate positive regulation, while bars indicate negative regulation. The dotted lines indicate either indirect regulation or regulation in an unknown manner. Bold arrows and bars indicate the events favoured under shade conditions

can physically interact with SPL9/15 and inhibit their transcriptional activation activities on BRC1 (Xie et al., 2020a). Additionally, SMXLs can also interact with BES1 and repress its transcriptional activation activity on $B R C 1$ to regulate branching (Hu et al. 2020). Taken together, shade decreases the protein abundance of FHY3/FAR1 and attenuates the expression of $S M X L 6 / 7$, relieving SPL9/15 and BES1 proteins to activate $B R C 1$, thus repressing branching (Fig. 4).

Shade-induced suppression of branching also involves the action of the phytohormone ABA (Fig. 4). Under shade conditions, ABA concentration and signaling particularly in lower buds are increased partly through PIF4/5-mediated upregulation of some ABA biosynthetic and responsive genes. Consistently, ABA synthesis mutants exhibit increased branching and lack of responsiveness to low R/FR (Holalu et al. 2020; Reddy et al. 2013). However, ABA-mediated inhibition of branching might not act through the $B R C 1$ pathway, as exogenous $A B A$ treatment does not alter $B R C 1$ level (Yao et al. 2015). Instead, ABA was shown to act downstream of BRC1 to suppress bud development (GonzálezGrandío et al., 2017). Interestingly, IAA accumulation as well as expression of auxin biosynthetic and transport genes are repressed by ABA treatment, suggesting that auxin is involved in ABA-mediated repression of bud outgrowth. Additionally, it has been shown that FHY3 and FAR1 are positive regulators of ABA signaling, as ABA sensitivity as well as expression of ABA responsive genes are attenuated in the fhy 3 and far 1 mutants (Tang et al. 2013). Thus, it will be interesting to explore the connection between FHY3/FAR1 and ABA-mediated branching suppression.

\section{The action of light, miR156/SPL and GA in flowering}

Flowering is a major developmental transition in the plant life cycle, and proper flowering time control is essential for plants' reproductive success and survival (Amasino and Michaels 2010). In response to competition for light from their neighbors, shade-intolerant plants flower precociously to ensure reproductive success and survival. The Arabidopsis wild-type plants subjected to low R/FR-treatment and phyB mutants grown under high R/FR demonstrate accelerated flowering (Wollenberg et al. 2008). The underlying mechanism involves promoted expression and protein stability of the core flowering regulator CONSTANS (CO), which acts to induce expression of the florigen gene FLOWERING LOCUS $T$ (FT) and its close homolog TWIN SYSTER OF FT (TSF) (Halliday et al. 2003; Valverde et al. 2004; Wollenberg et al. 2008). It was recently shown that PIF4, PIF5 and PIF7 play a predominate role in shade-induced flowering, through directly upregulating FT/TSF while downregulating Pri-MIR156E/F (Zhang et al. 2019; Galvāo et al. 2019). In addition, it was shown that under shade conditions, GA-mediated degradation of DELLA relieves their inhibition on PIF4, which in turn activates FT transcription to promote flowering (De Lucas et al. 2008; Kumar et al. 2012; Yamaguchi et al. 2014).

FHY3 and FAR1 were shown to negatively regulate flowering time under both long-day and short-day conditions through transcriptional regulation of Early Flowering4 (ELF4) (Li et al. 2011). A recent study revealed that FHY3 and FAR1 can physically interact 
with three flowering-promoting SPL transcription factors (SPL3, SPL4, SPL5) and inhibit their binding to the promoters of several key flowering regulatory genes, including FRUITFUL (FUL), LEAFY (LFY), APETALA1 (AP1), and $M I R 172 C$, thus downregulating their transcript levels and delaying flowering. Under simulated shade treatments, the levels of transcripts and proteins of FHY3 and FAR1 decrease, and thus more SPL3/4/5 proteins are released from inhibitory interactions with FHY3 protein, resulting in increased expression of FUL/ $L F Y / A P 1 / M I R 172 C$ and thus early flowering (Xie et al. 2020b) (Fig. 5).

\section{The action of JA and SA in shade mediated growth-defense tradeoff}

Another important aspect of SAS is attenuated resistance to abiotic and biotic stresses, as limited resources are reallocated from defense toward rapid elongation under shade conditions (de Wit et al. 2013). Resistance

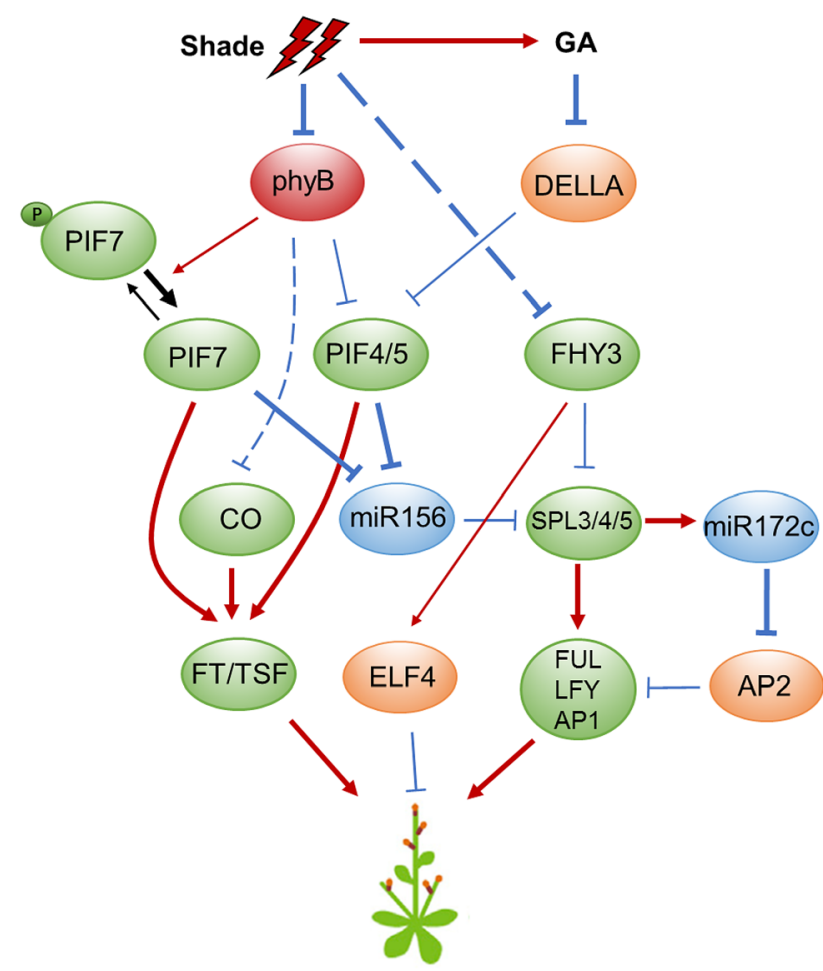

Fig. 5 The network of shade-regulated flowering time. Upon shade light, the increased activity and abundance of PIFs and CO lead to upregulation of FT or TSF, thus accelerating flowering. Additionally, SPL3/4/5 are released from repression by FHY3 and miR156, which in turn promotes flowering through upregulating several flowering promoting factors, such as FUL, $L F Y, A P 1$ and miR172. Arrows indicate positive regulation, while bars indicate negative regulation. The dotted lines indicate either indirect regulation or regulation in an unknown manner. Bold arrows and bars indicate the events favoured under shade conditions against a hemibiotrophic pathogen (Pseudomonas syringae pv tomato) and a necrotrophic pathogen (Botrytis cinerea) was found to be suppressed by shade treatment (Cerrudo et al. 2012; de Wit et al. 2013; Pieterse 2013). JA is a core regulatory hormone that orchestrates defense response against insects and necrotrophic pathogens (Browse 2009). It is known that low R/FR ratios repress JA-induced defense responses, including JA signaling and the expression of defense-related genes against herbivores and pathogens. Under shade conditions, inactivation of phyB results in attenuated JA sensitivity through promoting the stability of PIFs and JAZ proteins, while destabilizing DELLA proteins, thus relieving PIFs and JAZs from the inhibitory effect of DELLAs and allowing them to activate downstream genes and promote growth at the expense of defense (Cerrudo et al. 2012; Cortés et al. 2016; de Wit et al. 2013; Moreno et al. 2009; Yang et al. 2012) (Fig. 6). Besides PIFs, FHY3 and FAR1 were recently shown to modulate JA-mediated defense responses, as FHY3 and FAR1 are able to interact with both JAZs and MYC2 (Liu et al. 2019). Interestingly, the fhy3 far1 mutant displayed reduced JA sensitivity and increased susceptibility to necrotrophic fungus Botrytis cinerea under both high and low R/FR conditions. Consistently, expression of several typical JA-responsive genes, including LOX2, $P D F 1.2, T A T 1$, and VSP2, was significantly reduced in the fhy3 far 1 mutant. The transcription activation of JA responsive genes by FHY3 can be repressed by JAZ1 through direct interaction. In parallel, FHY3 and MYC2 form heterodimers and coordinately induce the expression of JA-responsive genes. The dual functions of FHY3 in regulating growth and defense under shade conditions indicate that plants balance their growth and defense responses through the convergence of the phytochrome signaling and JA signaling pathways. On one hand, FHY3 and FAR1 activate the expression of PAR1/PAR2, which inhibit the expression of growth-related genes by forming non-DNA binding heterodimers with PIFs, thus preventing an exaggerated elongation growth. On the other hand, FHY3/FAR1, together with MYC2, activate the expression of defense-associated genes, while JAZ proteins inhibit the activity of FHY3/ FAR1 and MYC2 to maintain a proper level of defense gene expression and defense response (Liu et al. 2019).

In addition to JA, salicylic acid (SA)-dependent disease resistance is also inhibited by reduced R/FR ratios (Fig. 6). Although SA level is not altered under low R/FR light, SA-dependent phosphorylation of NPR1, a key transcriptional regulator of SA-mediated defence, is reduced, thus resulting in inhibition of SA-induced transcription of disease resistance-related genes (de Wit et al. 2013; Nozue et al. 2018). 


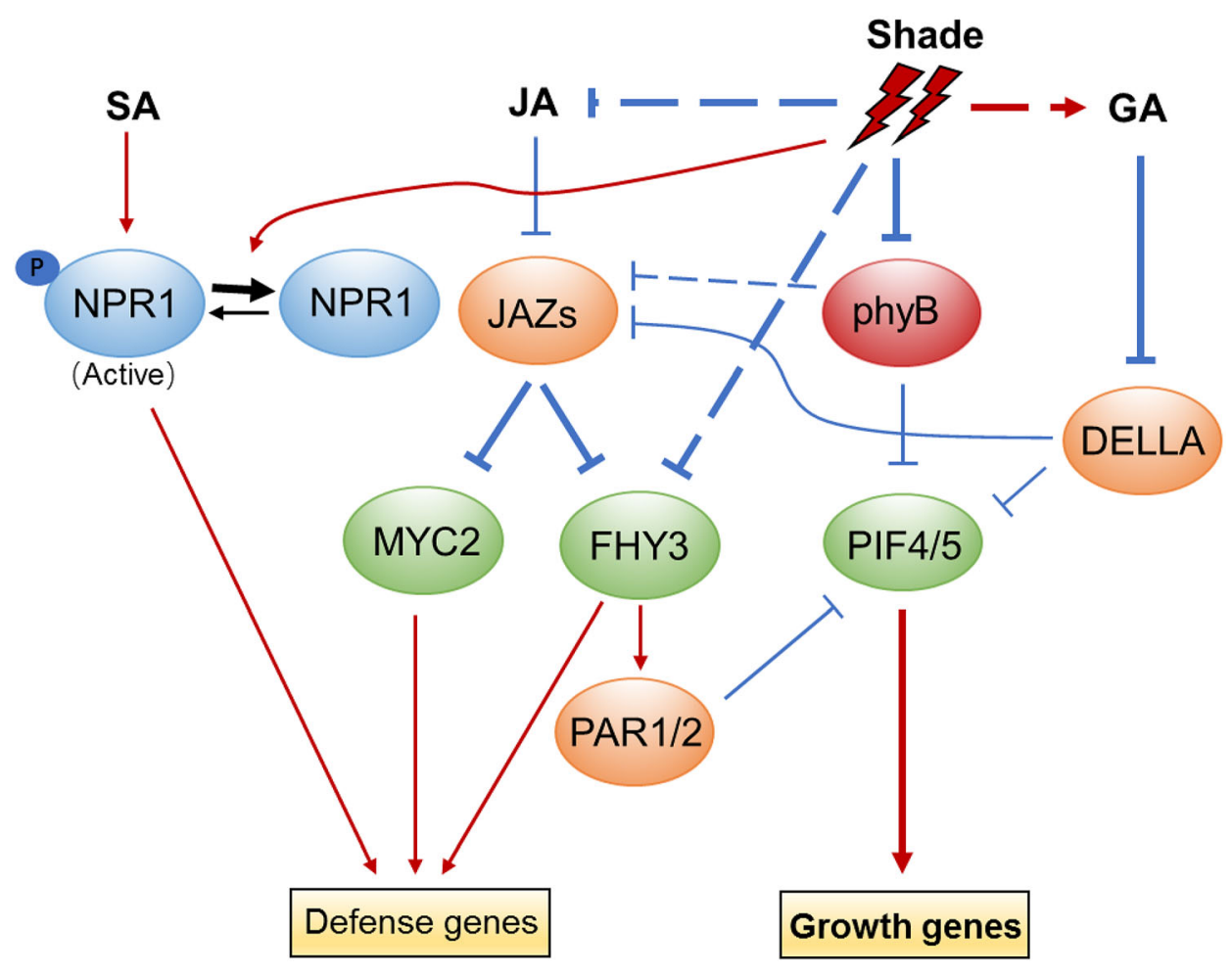

Fig. 6 The action of JA and SA in shade-mediated growth and defense tradeoff. The phosphorylated NPR1, which is the active form in SA signaling is reduced under shade conditions. Due to reduced JA level and the repression of phyB and DELLA in shade conditions, JAZ proteins are stabilized and are able to repress the transcriptional activity of MYC2 and FHY3. Therefore, SA- and JA-related targets of defense-responsive gene expression are reduced. Meanwhile, PIF4 and PIF5 are accumulated and released from repression by DELLA and PAR1/2, thus promoting growth-related target genes expression. Arrows indicate positive regulation, while bars indicate negative regulation. The dotted lines indicate either indirect regulation or regulation in an unknown manner. Bold arrows and bars indicate the events favoured under shade conditions

\section{Light and ethylene signaling modulates senescence}

The volatile hormone ethylene has also been shown to act as a proximity perception signal within canopies. Low R/FR-induced petiole elongation is absent in the ethylene signaling mutants ein2 and ein 3 eil1, indicating a requirement of the intact ethylene signaling pathway for shade avoidance response in Arabidopsis (Pierik et al. 2009). In accordance with this, transgenic tobacco lacking sensitivity to ethylene showed delayed shadeavoidance traits including leaf angles and stem elongation in response to shade signal (Pierik et al. 2003). Presumably, ethylene signaling acts downstream of photoreceptors to regulate SAS (Pierik et al. 2004, 2007). In support of this notion, Shi et al. (2016) showed that light-activated phyB can physically interact with EIN3 and lead to its rapid degradation. Thus, low $\mathrm{R} / \mathrm{FR}$ conditions may stabilize EIN3 due to inactivation of phyB, and in turn promoting SAS.

Another important effect of shade on the whole plant is precocious leaf senescence, a process of aging triggered by ethylene (Fig. 7). It was shown that leaf senescence is attributable to accelerated degradation of chlorophylls and proteins under shade conditions (Brouwer et al. 2012). Consistently, it has been shown that PIF4 negatively regulates chloroplast activity through activating expression of the chlorophyll degradation gene Non-yellowing 1 (NYE1) and repressing expression of the chloroplast activity maintainer gene Golden 2-like Transcription factor 2 (GLK2) (Song et al. 2014). In addition, PIF4 and PIF5 are able to promote dark-induced senescence through directly activating ethylene biosynthesis genes and key transcription factors of the ethylene and ABA signaling pathways, such as ACSs, EIN3 and ABI5, thereby activating downstream senescence-related targets, such as ORE1. Photoactivated phyB can inhibit leaf senescence through repressing leaf senescence activators PIF4/PIF5 at the post-translational level (Sakuraba et al. 2014; Song et al. 2014). A recent report revealed that the fhy 3 and far 1 mutants also exhibit precocious leaf senescence in both high and low R/FR light conditions, indicating a negative role of FHY3/FAR1 in regulating leaf senescence (Tian et al. 2020). It was shown that one mechanism of FHY3/FAR1 suppressing senescence is through 


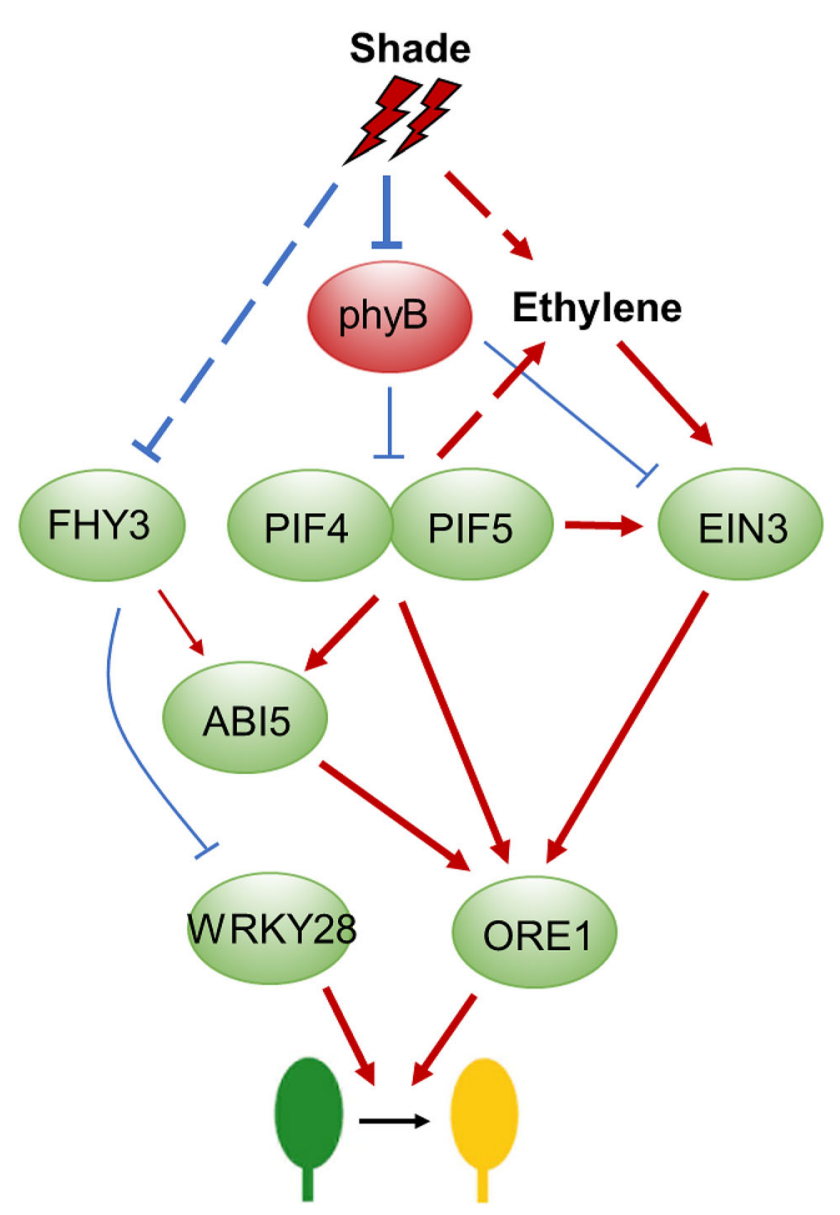

Fig. 7 Integration of light with ethylene promotes senescence under shade conditions. Under shade conditions, the activity and abundance PIF4/5 and EIN3 are increased by the action of ethylene or shade light. As a result, the key senescence regulator ORE1 is up-regulated directly by PIF4/5, EIN3 and ABI5. Meanwhile, WRKY28 is relieved from FHY3 repression. Therefore, the upregulated ORE1 and WRKY28 promote senescence under shade light. Arrow indicates positive regulation, while bar indicates negative regulation. The dotted lines indicate either indirect regulation or regulation in an unknown manner. Bold arrows and bars indicate the events favoured under shade conditions

repressing the expression of $W R K Y 28$, a positive regulator of senescence (Tian et al. 2020). Given the demonstrated interaction between FHY3/FAR1 with PIFs (Liu et al. 2020), it will be interesting to investigate how these two sets of SAS molecules act coordinately to regulate leaf senescence in the future.

\section{PERSPECTIVE AND CONCLUSIONS}

This review summarizes our present understanding of the integration of light and hormone signaling pathways in the regulation of multiple physiological responses of SAS in Arabidopsis. It is hoped that such knowledge can be leveraged to increase our understanding of SAS in various crops. Due to the global climate change and rising population, improvement of yield production per unit area is becoming increasingly important. Much effort has been devoted to breeding crops with the increased yield at high-planting density. However, SAS in crops can be detrimental to yield, due to increased lodging, reduced biomass production, precocious maturation and reduced defense to pathogens, etc. Therefore, SAS needs to be attenuated for genetic improvement of crops.

Indeed, much effort has been made to attenuate SAS in several crops such as rice, wheat, potato, tomato, and turfgrasses by overexpressing $P H Y A$ or $P H Y B$. In most case, limited success has been achieved due to associated pleiotropic effects (Boccalandro et al. 2003; Boylan and Quail 1989; Ganesan et al. 2012; Garg et al. 2006; Gururani et al. 2015; Robson et al. 1996; Thiele et al. 1999). Thus, a better understanding of SAS in various crops is urgently needed to fine-tune SAS and tailor plant architecture for adapting to high-density planting. Several recent studies have made progress to meet this need. A recent study reported that overexpression of GmCRY1b in soybean conferred improved plant architecture (such as reduced plant height, and thus more lodging-resistant) and higher yield performance under density planting or maize-soybean intercropping conditions. Moreover, it was shown that GmCRY1s play important roles in mediating LBL-induced SAS through modulating GA metabolism (Lyu et al. 2020). Other studies in maize reported that the Zmphyb1 Zmphyb2 double mutant displays constitutive shade avoidance responses, while Zmphyc1 Zmphyc2 double mutant shows moderately early flowering under long-day conditions (Kebrom et al. 2006; Li et al. 2020; Sheehan et al. 2007). Furthermore, expression of these two hyperactive mutant forms of $Z m P H Y B 1$ or overexpression of ZmPHYCs effectively reduces the plant height and ear height of mature maize plants in field conditions ( $\mathrm{Li}$ et al. 2020; Zhao et al. 2020). Additionally, the Zmpifs knockout mutants also display attenuated SAS and reduce plant and ear height effectively (Wu et al. 2019). Despite the progress been made, much more work remains to be done to provide a comprehensive understanding of SAS in crops and to identify valuable targets for genetic improvement of SAS. As various hormones are intimately involved in regulating different aspects of SAS, components of their signaling pathways may provide valuable targets for more precise manipulation of the various agronomic traits of crops (such as biomass, plant height, branches, leaf angle, leaf size, senescence, flowering time, etc.). On the other hand, tapping into the rich resource of natural variation of crop germplasm using population genetics approaches 
may offer an alternative approach to identify the superior alleles associated with attenuated SAS for breeding shade-tolerant crop cultivars (Wang et al. 2020). With the rapid advances in plant functional genomics, genome editing technologies and synthetic biology, more tools and resources will become available to meet the challenge of breeding high-density tolerant crops with higher efficiency.

Acknowledgements We thank Dr. Lin Li (Fudan University), Dr. Yurong Xie (Chinese Academy of Agricultural Sciences), Dr. Hongbin Wei and Dr. Yingying Cao (South China Agricultural University) for valuable comments on this manuscript. This work was supported by the National Natural Science Foundation of China (31921004), National Science Foundation of China-Guangdong Province Collaborative Project (U1701232) and the Major Program of Guangdong Basic and Applied Research (2019B030302006).

\section{Compliance with ethical standards}

Conflict of interest On behalf of all authors, the corresponding author states that there is no conflict of interest.

Open Access This article is licensed under a Creative Commons Attribution 4.0 International License, which permits use, sharing, adaptation, distribution and reproduction in any medium or format, as long as you give appropriate credit to the original author(s) and the source, provide a link to the Creative Commons licence, and indicate if changes were made. The images or other third party material in this article are included in the article's Creative Commons licence, unless indicated otherwise in a credit line to the material. If material is not included in the article's Creative Commons licence and your intended use is not permitted by statutory regulation or exceeds the permitted use, you will need to obtain permission directly from the copyright holder. To view a copy of this licence, visit http://creativecommons.org/ licenses/by/4.0/.

\section{References}

Ahmad M, Cashmore AR (1993) HY4 gene of A. thaliana encodes a protein with characteristics of a blue-light photoreceptor. Nature 366:162-166. https://doi.org/10.1038/366162a0

Al-Sady B, Ni W, Kircher S, Schäfer E, Quail PH (2006) Photoactivated phytochrome induces rapid PIF3 phosphorylation prior to proteasome-mediated degradation. Mol Cell 23:439-446. https://doi.org/10.1016/j.molcel.2006.06.011

Amasino RM, Michaels SD (2010) The timing of flowering. Plant Physiol 154:516-520. https://doi.org/10.1104/pp.110. 161653

Bai MY et al (2012) Brassinosteroid, gibberellin and phytochrome impinge on a common transcription module in Arabidopsis. Nat Cell Biol 14:810-817. https://doi.org/10.1038/ncb2546

Ballaré CL (2014) Light regulation of plant defense. Annu Rev Plant Biol 65:335-363. https://doi.org/10.1146/annurevarplant-050213-040145

Blanco-Touriñán N et al (2020) COP1 destabilizes DELLA proteins in Arabidopsis. Proc Natl Acad Sci USA 117:13792-13799. https://doi.org/10.1073/pnas.1907969117
Boccaccini A et al (2020) Low blue light enhances phototropism by releasing cryptochrome1-mediated inhibition of PIF4 expression. Plant Physiol 183:1780-1793. https://doi.org/ 10.1104/pp.20.00243

Boccalandro HE, Ploschuk EL, Yanovsky MJ, Sánchez RA, Gatz C, Casal JJ (2003) Increased phytochrome B alleviates density effects on tuber yield of field potato crops. Plant Physiol 133:1539-1546. https://doi.org/10.1104/pp.103.029579

Bou-torrent J, Galstyan A, Martret S, Roig-villanova I, Ruberti I, Mart JF (2013) The bHLH proteins BEE and BIM positively modulate the shade avoidance syndrome in Arabidopsis seedlings. Plant J 75:989-1002. https://doi.org/10.1111/ tpj.12264

Bou-torrent J, Martinez-garcia JF, Galstyan A (2011) The shade avoidance syndrome in Arabidopsis: a fundamental role for atypical basic helix-loop-helix proteins as transcriptional cofactors. Plant J 66:258-267. https://doi.org/10.1111/j. 1365-313X.2011.04485.x

Bouré N, Kumar SV, Arnaud N (2019) The BAP module: a multisignal integrator orchestrating growth. Trends Plant Sci 24:602-610. https://doi.org/10.1016/j.tplants.2019.04.002

Boylan MT, Quail PH (1989) Oat phytochrome is biologically active in transgenic tomatoes. Plant Cell 1:765-773. https://doi. org/10.2307/3868985

Brouwer B, Ziolkowska A, Bagard M, Keech 0, Gardeström P (2012) The impact of light intensity on shade-induced leaf senescence. Plant Cell Environ 35:1084-1098. https://doi. org/10.1111/j.1365-3040.2011.02474.x

Browse J (2009) Jasmonate passes muster: A receptor and targets for the defense hormone. Annu Rev Plant Biol 60:183-205. https://doi.org/10.1146/annurev.arplant.043008.092007

Buti S, Hayes S, Pierik R (2020) The bHLH network underlying plant shade-avoidance. Physiol Plant 169:312-324. https:// doi.org/10.1111/ppl.13074

Casal JJ (2013) Photoreceptor signaling networks in plant responses to shade. Annu Rev Plant Biol 64:403-427. https://doi.org/10.1146/annurev-arplant-050312-120221

Cerrudo I et al (2012) Low red/far-red ratios reduce arabidopsis resistance to Botrytis cinerea and jasmonate responses via a COI1-JAZ10-dependent, salicylic acid-independent mechanism. Plant Physiol 158:2042-2052. https://doi.org/10. 1104/pp.112.193359

Chang CS, Maloof JN, Wu SH (2011) COP1-mediated degradation of BBX22/LZF1 optimizes seedling development in Arabidopsis. Plant Physiol 156:228-239. https://doi.org/10.1104/pp. 111.175042

Cortés LE, Weldegergis BT, Boccalandro HE, Dicke M, Ballaré CL (2016) Trading direct for indirect defense? Phytochrome B inactivation in tomato attenuates direct anti-herbivore defenses whilst enhancing volatile-mediated attraction of predators. New Phytol 212:1057-1071. https://doi.org/10. 1111/nph.14210

Crocco CD, Holm M, Yanovsky MJ, Botto JF (2010) AtBBX21 and COP1 genetically interact in the regulation of shade avoidance. Plant J 64:551-562. https://doi.org/10.1111/j.1365313X.2010.04360.X

Crocco CD, Locascio A, Escudero CM, Alabadı D, Botto JF (2015) The transcriptional regulator BBX24 impairs DELLA activity to promote shade avoidance in Arabidopsis thaliana. Nat Commun 6:6202. https://doi.org/10.1038/ncomms7202

Davière JM, Achard P (2013) Gibberellin signaling in plants Development 140:1147-1151. https://doi.org/10.1242/dev. 087650

De Lucas M et al (2008) A molecular framework for light and gibberellin control of cell elongation. Nature 451:480-484. https://doi.org/10.1038/nature06520 
de Wit $M$ et al (2016) Integration of phytochrome and cryptochrome signals determines plant growth during competition for light. Curr Biol 26:3320-3326. https://doi.org/10. 1016/j.cub.2016.10.031

de Wit M et al (2013) Perception of low red: far-red ratio compromises both salicylic acid- and jasmonic acid-dependent pathogen defences in Arabidopsis. Plant J 75:90-103. https://doi.org/10.1111/tpj.12203

Djakovic-Petrovic T, de Wit M, Voesenek LA, Pierik R (2007) DELLA protein function in growth responses to canopy signals. Plant J 51:117-126. https://doi.org/10.1111/j.1365313X.2007.03122.X

Dodd AN et al (2005) Plant circadian clocks increase photosynthesis, growth, survival, and competitive advantage. Science 309:630-633. https://doi.org/10.1126/science.1115581

Feng S et al (2008) Coordinated regulation of Arabidopsis thaliana development by light and gibberellins. Nature 451:475-479. https://doi.org/10.1038/nature06448

Finlayson SA, Krishnareddy SR, Kebrom TH, Casal JJ (2010) Phytochrome regulation of branching in Arabidopsis. Plant Physiol 152:1914-1927. https://doi.org/10.1104/pp.109. 148833

Franklin KA (2008) Shade avoidance. New Phytol 179:930-944. https://doi.org/10.1111/j.1469-8137.2008.02507.x

Franklin KA, Praekelt U, Stoddart WM, Billingham OE, Halliday KJ, Whitelam GC (2003) Phytochromes B, D, and E act redundantly to control multiple physiological responses in Arabidopsis. Plant Physiol 131:1340-1346. https://doi.org/10. 1104/pp.102.015487

Galstyan A, Cifuentes-Esquivel N, Bou-Torrent J, Martinez-Garcia JF (2011) The shade avoidance syndrome in Arabidopsis: a fundamental role for atypical basic helix-loop-helix proteins as transcriptional cofactors. Plant J 66:258-267. https://doi. org/10.1046/j.1365-313X.2011.04485.X

Galvāo VC et al (2019) PIF transcription factors link a neighbor threat cue to accelerated reproduction in Arabidopsis. Nat Commun 10:4005. https://doi.org/10.1038/s41467-01911882-7

Ganesan M et al (2012) Overexpression of phytochrome A and its hyperactive mutant improves shade tolerance and turf quality in creeping bentgrass and zoysiagrass. Planta 236:1135-1150. https://doi.org/10.1007/s00425-012$1662-6$

Gangappa SN, Crocco CD, Johansson H, Datta S, Hettiarachchi C, Holm M, Botto JF (2013) The Arabidopsis B-BOX protein BBX25 interacts with HY5, negatively regulating BBX22 expression to suppress seedling photomorphogenesis. Plant Cell 25:1243-1257. https://doi.org/10.1105/tpc.113.109751

Garg AK et al (2006) Light-regulated overexpression of an Arabidopsis phytochrome A gene in rice alters plant architecture and increases grain yield. Planta 223:627-636. https://doi.org/10.1007/s00425-005-0101-3

González-Grandío E, Pajoro A, Franco-Zorrilla JM, Tarancón C, Immink RG, Cubas P (2017) Abscisic acid signaling is controlled by a BRANCHED1/HD-ZIP I cascade in Arabidopsis axillary buds. Proc Natl Acad Sci USA 114:E245-E254. https://doi.org/10.1073/pnas.1613199114

Goyal A, Karayekov E, Galvão VC, Ren H, Casal JJ, Fankhauser C (2016) Shade promotes phototropism through phytochrome B-controlled auxin production. Curr Biol 26:3280-3287. https://doi.org/10.1016/j.cub.2016.10.001

Guo H, Yang H, Mockler TC, Lin C (1998) Regulation of flowering time by Arabidopsis photoreceptors. Science 279:1360-1363. https://doi.org/10.1126/science.279.5355.1360
Gururani MA, Ganesan M, Song PS (2015) Photo-biotechnology as a tool to improve agronomic traits in crops. Biotechnol Adv 33:53-63. https://doi.org/10.1016/j.biotechadv.2014.12.005

Halliday KJ, Salter MG, Thingnaes E, Whitelam GC (2003) Phytochrome control of flowering is temperature sensitive and correlates with expression of the floral integrator FT. Plant J 33:875-885. https://doi.org/10.1046/j.1365-313X. 2003.01674.x

Hao Y, Oh E, Choi G, Liang Z, Wang ZY (2012) Interactions between HLH and bHLH factors modulate light-regulated plant development. Mol Plant 5:688-697. https://doi.org/10.1093/mp/ $\operatorname{sss} 011$

Hayes S et al (2019) Soil salinity limits plant shade avoidance. Curr Biol 29:1669-1676. https://doi.org/10.1016/j.cub. 2019.03.042

Hayes S, Velanis CN, Jenkins GI, Franklin KA (2014) UV-B detected by the UVR8 photoreceptor antagonizes auxin signaling and plant shade avoidance. Proc Natl Acad Sci USA 111:11894-11899. 1403052111

Hisamatsu T, King RW, Helliwell CA, Koshioka M (2005) The involvement of gibberellin 20-oxidase genes in phytochromeregulated petiole elongation of Arabidopsis. Plant Physiol 138:1106-1116. https://doi.org/10.1104/pp.104.059055

Holalu SV, Reddy SK, Blackman BK, Finlayson SA (2020) Phytochrome interacting factors 4 and 5 regulate axillary branching via bud abscisic acid and stem auxin signalling. Plant Cell Environ 43:2224-2238. https://doi.org/10.1111/ pce.13824

Hornitschek P et al (2012) Phytochrome interacting factors 4 and 5 control seedling growth in changing light conditions by directly controlling auxin signaling. Plant J 71:699-711. https://doi.org/10.1111/j.1365-313X.2012.05033.x

Hornitschek P, Lorrain S, Zoete V, Michielin O, Fankhauser C (2009) Inhibition of the shade avoidance response by formation of non-DNA binding bHLH heterodimers. EMBO J 28:3893-3902. https://doi.org/10.1093/emboj.2009.306

Hu J, Ji Y, Hu X, Sun S, Wang X (2020) BES1 functions as the coregulator of D53-like SMXLs to inhibit BRC1 expression in strigolactone-regulated shoot branching in Arabidopsis. Plant Commun 1:100014. https://doi.org/10.1016/j.xplc.2019. 100014

Huang X, Zhang Q Jiang Y, Yang C, Wang Q Li L (2018) Shadeinduced nuclear localization of PIF7 is regulated by phosphorylation and 14-3-3 proteins in Arabidopsis. eLife 7:e31636. https://doi.org/10.7554/eLife.31636

Iglesias MJ, Sellaro R, Zurbriggen MD, Casal JJ (2018) Multiple links between shade avoidance and auxin networks. J Exp Bot 69:213-228. https://doi.org/10.1093/jxb/erx295

Indorf M, Cordero J, Neuhaus G, Rodríguez-Franco M (2007) Salt tolerance (STO), a stress-related protein, has a major role in light signalling. Plant J 51:563-574. https://doi.org/10.1111/ j.1365-313X.2007.03162.x

Jiao Y et al (2010) Regulation of OsSPL14 by OsmiR156 defines ideal plant architecture in rice. Nat Genet 42:541-544. https://doi.org/10.1038/ng.591

Kaiserli E, Jenkins GI (2007) UV-B promotes rapid nuclear translocation of the Arabidopsis UV-B-specific signaling component UVR8 and activates its function in the nucleus. Plant Cell 19:2662-2673. https://doi.org/10.1105/tpc.107. 053330

Kebrom TH, Burson BL, Finlayson SA (2006) Phytochrome B represses Teosinte Branched1 expression and induces sorghum axillary bud outgrowth in response to light signals. Plant Physiol 140:1109-1117. https://doi.org/10.1104/pp. 105.074856 
Keller MM, Jaillais Y, Pedmale UV, Moreno JE, Chory J, Ballaré CL (2011) Cryptochrome 1 and phytochrome B control shadeavoidance responses in Arabidopsis via partially independent hormonal cascades. Plant J 67:195-207. https://doi.org/10. 1111/j.1365-313X.2011.04598.x

Keuskamp DH, Pollmann S, Voesenek LA, Peeters AJ, Pierik R (2010) Auxin transport through PIN-FORMED 3 (PIN3) controls shade avoidance and fitness during competition. Proc Natl Acad Sci USA 107:22740-22744. https://doi.org/ 10.1073/pnas.1013457108

Keuskamp DH, Sasidharan R, Vos I, Peeters AJ, Voesenek LA, Pierik $R$ (2011) Blue-light-mediated shade avoidance requires combined auxin and brassinosteroid action in Arabidopsis seedlings. Plant J 67:208-217. https://doi.org/10.1111/j. 1365-313X.2011.04597.x

Kohnen MV et al (2016) Neighbor detection induces organ-specific transcriptomes, revealing patterns underlying hypocotylspecific growth. Plant Cell 28:2889-2904. https://doi.org/ $10.1105 /$ tpc. 16.00463

Kumar SV, Lucyshyn D, Jaeger KE, Alós E, Alvey E, Harberd NP, Wigge PA (2012) Transcription factor PIF4 controls the thermosensory activation of flowering. Nature 484:242-245. https://doi.org/10.1038/nature10928

Kunihiro A, Yamashino T, Nakamichi N, Niwa Y, Nakanishi H, Mizuno T (2011) PHYTOCHROME-INTERACTING FACTOR 4 and 5 (PIF4 and PIF5) activate the Homeobox ATHB2 and auxin-inducible IAA29 genes in the coincidence mechanism underlying photoperiodic control of plant growth of Arabidopsis thaliana. Plant Cell Physiol 52:1315-1329. https:// doi.org/10.1093/pcp/pcr076

Lau OS, Deng XW (2010) Plant hormone signaling lightens up: integrators of light and hormones. Curr Opin Plant Biol 13:571-577. https://doi.org/10.1016/j.pbi.2010.07.001

Leivar P et al (2008) The Arabidopsis phytochrome-interacting factor PIF7, together with PIF3 and PIF4, regulates responses to prolonged red light by modulating phyB levels. Plant Cell 20:337-352. https://doi.org/10.1105/tpc.107.052142

Leone M, Keller MM, Cerrudo I, Ballaré CL (2014) To grow or defend? Low red: Far-red ratios reduce jasmonate sensitivity in Arabidopsis seedlings by promoting DELLA degradation and increasing JAZ10 stability. New Phytol 204:355-367. https://doi.org/10.1111/nph.12971

Li G et al (2011) Coordinated transcriptional regulation underlying the circadian clock in Arabidopsis. Nat Cell Biol 13:616-622. https://doi.org/10.1038/ncb2219

Li L et al (2012) Linking photoreceptor excitation to changes in plant architecture. Genes Dev 26:785-790. https://doi.org/ 10.1101/gad.187849.112

Li Q et al (2020) CRISPR/Cas9-mediated knockout and overexpression studies reveal a role of maize phytochrome $C$ in regulating flowering time and plant height. Plant Biotechnol J 18:2520-2532. https://doi.org/10.1111/pbi.13429

Lin R, Ding L, Casola C, Ripoll DR, Feschotte C, Wang H (2007) Transposase-derived transcription factors regulate light signaling in Arabidopsis. Science 318:1302-1305. https://doi. org/10.1126/science.1146281

Ling JJ, Li J, Zhu D, Deng XW (2017) Noncanonical role of Arabidopsis COP1/SPA complex in repressing BIN2-mediated PIF3 phosphorylation and degradation in darkness. Proc Natl Acad Sci USA 114:3539-3544. https://doi.org/10.1073/pnas. 1700850114

Liu B, Zuo Z, Liu H, Liu X, Lin C (2011) Arabidopsis cryptochrome 1 interacts with SPA1 to suppress COP1 activity in response to blue light. Genes Dev 25:1029-1034. https://doi.org/10. 1101/gad.2025011
Liu Y et al (2020) Transcription factors FHY3 and FAR1 regulate light-induced CIRCADIAN CLOCK ASSOCIATED1 gene expression in Arabidopsis. Plant Cell 32:1464-1478. https://doi. org/10.1105/tpc.19.00981

Liu Y et al (2019) Arabidopsis FHY3 and FAR1 regulate the balance between growth and defense responses under shade conditions. Plant Cell 31:2089-2106. https://doi.org/10. 1105/tpc.18.00991

Lorrain S, Allen T, Duek PD, Whitelam GC, Fankhauser C (2008) Phytochrome-mediated inhibition of shade avoidance involves degradation of growth-promoting bHLH transcription factors. Plant J 53:312-323. https://doi.org/10.1111/j. 1365-313X.2007.03341.x

Lyu X et al (2020) GmCRY1s modulate gibberellin metabolism to regulate Soybean shade avoidance in response to reduced blue light. Mol Plant 26:S1674-2052. https://doi.org/10. 1016/j.molp.2020.11.016

Mao Z et al (2020) Photoexcited CRY1 and phyB interact directly with ARF6 and ARF8 to regulate their DNA-binding activity and auxin-induced hypocotyl elongation in Arabidopsis. New Phytol 225:848-865. https://doi.org/10.1111/nph.16194

Mao Z et al (2020) Photoexcited CRY1 and phyB interact directly with ARF6 and ARF8 to regulate their DNA-binding activity and auxin-induced hypocotyl elongation in Arabidopsis. New Phytol 225:848-865. https://doi.org/10.1111/nph.16194

Martínez C, Espinosa-Ruíz A, de Lucas M, Bernardo-García S, Franco-Zorrilla JM, Prat S (2018) PIF4-induced BR synthesis is critical to diurnal and thermomorphogenic growth. EMBO J 37:e99552. https://doi.org/10.15252/embj.201899552

Martínez-García JF, Gallemí M, Molina-Contreras MJ, Llorente B, Bevilaqua MR, Quail PH (2014) The shade avoidance syndrome in Arabidopsis: the antagonistic role of phytochrome A and B differentiates vegetation proximity and canopy shade. PLoS ONE 9:e109275. https://doi.org/10. 1371/journal.pone.0109275

Moreno JE, Tao Y, Chory J, Ballaré CL (2009) Ecological modulation of plant defense via phytochrome control of jasmonate sensitivity. Proc Natl Acad Sci USA 106:4935-4940. https:// doi.org/10.1073/pnas.0900701106

Nozue K, Devisetty UK, Lekkala S, Mueller-Moulé P, Bak A, Casteel CL, Maloof JN (2018) Network analysis reveals a role for salicylic acid pathway components in shade avoidance. Plant Physiol 178:1720-1732. https://doi.org/10.1104/pp.18. 00920

Nozue K, Tat AV, Devisetty UK, Robinson M (2015) Shade avoidance components and pathways in adult plants revealed by phenotypic profiling. PLoS Genet 11:e1004953. https:// doi.org/10.1371/journal.pgen.1004953

Oh E, Zhu JY, Bai MY, Arenhart RA, Sun Y, Wang ZY (2014) Cell elongation is regulated through a central circuit of interacting transcription factors in the Arabidopsis hypocotyl. eLife 3:e03031. https://doi.org/10.7554/eLife.03031

Osterlund MT, Hardtke CS, Wei N, Deng XW (2000) Targeted destabilization of HY5 during light-regulated development of Arabidopsis. Nature 405:462-466. https://doi.org/10.1038/ 35013076

Pacín M, Legris M, Casal JJ (2013) COP1 re-accumulates in the nucleus under shade. Plant J 75:631-641. https://doi.org/10. $1111 /$ tpj.12226

Pedmale UV et al (2016) Cryptochromes interact directly with PIFs to control plant growth in limiting blue light. Cell 164:233-245. https://doi.org/10.1016/j.cell.2015.12.018

Pham VN, Kathare PK, Huq E (2018) Dynamic regulation of PIF5 by COP1-SPA complex to optimize photomorphogenesis in Arabidopsis. Plant J 96:260-273. https://doi.org/10.1111/ tpj.14074 
Pierik R, Cuppens ML, Voesenek LA, Visser EJ (2004) Interactions between ethylene and gibberellins in phytochrome-mediated shade avoidance responses in tobacco. Plant Physiol 136:2928-2936. https://doi.org/10.1104/pp.104.045120

Pierik R, Djakovic-Petrovic T, Keuskamp DH, de Wit M, Voesenek LA (2009) Auxin and ethylene regulate elongation responses to neighbor proximity signals independent of gibberellin and DELLA proteins in Arabidopsis. Plant Physiol 149:1701-1712. https://doi.org/10.1104/pp.108.133496

Pierik R, Sasidharaz R, Voesenek LA (2007) Growth control by ethylene: Adjusting phenotypes to the environment. J Plant Growth Regul 26:188-200. https://doi.org/10.1007/s00344006-0124-4

Pierik R, Visser EJ, De Kroon H, Voesenek LA (2003) Ethylene is required in tobacco to successfully compete with proximate neighbours. Plant Cell Environ 26:1229-1234. https://doi. org/10.1046/j.1365-3040.2003.01045.x

Pieterse MJ (2013) Perception of low red: far-red ratio compromises both salicylic acid- and jasmonic acid-dependent pathogen defences in Arabidopsis. Plant J 75:90-103. https://doi.org/10.1111/tpj.12203

Procko C, Burko Y, Jaillais Y, Ljung K, Long JA, Chory J (2016) The epidermis coordinates auxin-induced stem growth in response to shade. Genes Dev 30:1529-1541. https://doi. org/10.1101/gad.283234.116

Procko C, Crenshaw CM, Ljung K, Noel JP, Chory J (2014) Cotyledon-generated auxin is required for shade-induced hypocotyl growth in brassica rapa. Plant Physiol 165:1285-1301. https://doi.org/10.1104/pp.114.241844

Pucciariello 0 et al (2018) Rewiring of auxin signaling under persistent shade. Proc Natl Acad Sci USA 115:5612-5617. https://doi.org/10.1073/pnas.1721110115

Reddy SK, Finlayson SA (2014) Phytochrome B promotes branching in Arabidopsis by suppressing auxin signaling. Plant Physiol 164:1542-1550. https://doi.org/10.1104/pp. 113.234021

Reddy SK, Holalu SV, Casal JJ, Finlayson SA (2013) Abscisic acid regulates axillary bud outgrowth responses to the ratio of red to far-red light. Plant Physiol 163:1047-1058. https://doi. org/10.1104/pp.113.221895

Rizzini L et al (2011) Perception of UV-B by the Arabidopsis UVR8 protein. Science 332:103-106. https://doi.org/10.1126/ science. 1200660

Robson PR, McCormac AC, Irvine AS, Smith H (1996) Genetic engineering of harvest index in tobacco through overexpression of a phytochrome gene. Nat Biotechnol 14:995-998. https://doi.org/10.1038/nbt0896-995

Roig-Villanova I, Bou J, Sorin C, Devlin PF, Martínez-García JF (2006) Identification of primary target genes of phytochrome signaling. Early transcriptional control during shade avoidance responses in Arabidopsis. Plant Physiol 141:85-96. https://doi.org/10.1104/pp.105.076331

Sakuraba Y, Jeong J, Kang MY, Kim J, Paek NC, Choi G (2014) Phytochrome-interacting transcription factors PIF4 and PIF5 induce leaf senescence in Arabidopsis. Nat Commun 5:4636. https://doi.org/10.1038/ncomms5636

Schmitt J (1997) Is photomorphogenic shade avoidance adaptive? Perspectives from population biology. Plant Cell Environ 20:826-830. https://doi.org/10.1046/j.1365-3040.1997. d01-96.x

Sellaro R, Yanovsky MJ, Casal JJ (2011) Repression of shadeavoidance reactions by sunfleck induction of HY5 expression in Arabidopsis. Plant J 68:919-928. https://doi.org/10.1111/ j.1365-313X.2011.04745.x

Seo HS, Yang JY, Ishikawa M, Bolle C, Ballesteros ML, Chua NH (2003) LAF1 ubiquitination by COP1 controls photomorphogenesis and is stimulated by SPA1. Nature 423:995-999. https://doi.org/10.1038/nature01696

Sharma A, Sharma B, Hayes S, Kerner K, Hoecker U, Jenkins GI, Franklin KA (2019) UVR8 disrupts stabilisation of PIF5 by COP1 to inhibit plant stem elongation in sunlight. Nat Commun 10:4417. https://doi.org/10.1038/s41467-01912369-1

Sheehan MJ, Kennedy LM, Costich DE, Brutnell TP (2007) Subfunctionalization of PhyB1 and PhyB2 in the control of seedling and mature plant traits in maize. Plant J 49:338-353. https://doi.org/10.1111/j.1365-313X.2006.02962.x

Shen Y, Khanna R, Carle CM, Quail PH (2007) Phytochrome induces rapid PIF5 phosphorylation and degradation in response to red-light activation. Plant Physiol 145:1043-1051. https://doi.org/10.1104/pp.107.105601

Shi H, Shen X, Liu R, Xue C, Wei N, Deng XW, Zhong S (2016) The red light receptor phytochrome $B$ directly enhances substrate-E3 ligase interactions to attenuate ethylene responses. Dev Cell 39:597-610. https://doi.org/10.1016/j.devcel.2016. 10.020

Song B et al (2020) Phytochrome A inhibits shade avoidance responses under strong shade through repressing the brassinosteroid pathway in Arabidopsis. Plant J 104:1520-1534. https://doi.org/10.1111/tpj.15018

Song X et al (2017) IPA1 functions as a downstream transcription factor repressed by D53 in strigolactone signaling in rice. Cell Res 27:1128-1141. https://doi.org/10.1038/cr.2017.102

Song Y, Yang C, Gao S, Zhang W, Li L, Kuai B (2014) Age-triggered and dark-induced leaf senescence require the bHLH transcription factors PIF3, 4, and 5. Mol Plant 7:1776-1787. https://doi.org/10.1093/mp/ssu109

Sun J, Qi L, Li Y, Chu J, Li C (2012) PIF4-mediated activation of YUCCA8 expression integrates temperature into the auxin pathway in regulating arabidopsis hypocotyl growth. PLoS Genet 8:e1002594. https://doi.org/10.1371/journal.pgen. 1002594

Tang W, Ji Q, Huang Y, Jiang Z, Bao M, Wang H, Lin R (2013) FARRED ELONGATED HYPOCOTYl3 and FAR-RED IMPAIRED RESPONSE1 transcription factors integrate light and abscisic acid signaling in Arabidopsis. Plant Physiol 163:857-866. https://doi.org/10.1104/pp.113.224386

Tavridou E, Pireyre M, Ulm R (2020a) Degradation of the transcription factors PIF4 and PIF5 under UV-B promotes UVR8-mediated inhibition of hypocotyl growth in Arabidopsis. Plant J 101:507-517. https://doi.org/10.1111/tpj.14556

Tavridou E, Schmid-Siegert E, Fankhauser C, Ulm R (2020) UVR8mediated inhibition of shade avoidance involves HFR1 stabilization in Arabidopsis. PLoS Genet 16:e1008797. https://doi.org/10.1371/journal.pgen.1008797

Thiele A, Herold M, Lenk I, Quail PH, Gatz C (1999) Heterologous expression of Arabidopsis phytochrome B in transgenic potato influences photosynthetic performance and tuber development. Plant Physiol 120:73-82. https://doi.org/10. 1104/pp.120.1.73

Tian T, Ma L, Liu Y, Xu D, Chen Q, Li G (2020) Arabidopsis FAR-RED ELONGATED HYPOCOTYL3 integrates age and light signals to negatively regulate leaf senescence. Plant Cell 32:1574-1588. https://doi.org/10.1105/tpc.20.00021

Valverde F, Mouradov A, Soppe W, Ravenscroft D, Samach A, Coupland G (2004) Photoreceptor regulation of CONSTANS protein in photoperiodic flowering. Science 303:1003-1006. https://doi.org/10.1126/science.1091761

Wang B et al (2020) Genome-wide selection and genetic improvement during modern maize breeding. Nat Genet 52:565-571. https://doi.org/10.1038/s41588-020-0616-3 
Wang B, Smith SM, Li J (2018) Genetic regulation of shoot architecture. Annu Rev Plant Biol 69:437-468. https://doi. org/10.1146/annurev-arplant-042817-040422

Wang H, Wang H (2015) Phytochrome signaling: time to tighten up the loose ends. Mol Plant 8:540-551. https://doi.org/10. 1016/j.molp.2014.11.021

Wang L et al (2015) Coordinated regulation of vegetative and reproductive branching in rice. Proc Natl Acad Sci USA 112:15504-15509. 1521949112

Wang M et al (2019) BRANCHED1: A key hub of shoot branching. Front Plant Sci 10:76. https://doi.org/10.3389/fpls.2019. 00076

Wang Q Lin C (2020) Mechanisms of cryptochrome-mediated photoresponses in plants. Annu Rev Plant Biol 71:103-129. https://doi.org/10.1146/annurev-arplant-050718-100300

Whitelam GC, Patel S, Devlin PF (1998) Phytochromes and photomorphogenesis in Arabidopsis. Philos Trans R Soc Lond B Biol Sci 353:1445-1453. https://doi.org/10.1098/rstb. 1998.0300

Wollenberg AC, Strasser B, Cerdán PD, Amasino RM (2008) Acceleration of flowering during shade avoidance in Arabidopsis alters the balance between Flowering Locus C-mediated repression and photoperiodic induction of flowering. Plant Physiol 148:1681-1694. https://doi.org/10.1104/pp. 108.125468

Wu G et al (2019) Characterization of maize phytochromeinteracting factors in light signaling and photomorphogenesis. Plant Physiol 181:789-803. https://doi.org/10.1104/pp. 19.00239

Xie $Y$ et al (2017) Phytochrome-interacting factors directly suppress MIR156 expression to enhance shade-avoidance syndrome in Arabidopsis. Nat Commun 8:348. https://doi. org/10.1038/s41467-017-00404-y

Xie Y et al (2020a) Arabidopsis FHY3 and FAR1 integrate light and strigolactone signaling to regulate branching. Nat Commun 11:1955. https://doi.org/10.1038/s41467-020-15893-7

Xie Y et al (2020b) FHY3 and FAR1 integrate light signals with the miR156-SPL module-mediated aging pathway to regulate Arabidopsis flowering. Mol Plant 13:483-498. https://doi. org/10.1016/j.molp.2020.01.013

Xu D, Jiang Y, Li J, Lin F, Holm M, Deng XW (2016) BBX21, an Arabidopsis B-box protein, directly activates HY5 and is targeted by COP1 for $26 \mathrm{~S}$ proteasome-mediated degradation.
Proc Natl Acad Sci USA 113:7655-7660. https://doi.org/10. 1073/pnas.1607687113

Xu F et al (2018) Photoactivated CRY1 and phyB interact directly with AUX/IAA proteins to inhibit auxin signaling in Arabidopsis. Mol Plant 11:523-541. https://doi.org/10.1016/j. molp.2017.12.003

Yamaguchi $\mathrm{N}$ et al (2014) Gibberellin acts positively then negatively to control onset of flower formation in Arabidopsis. Science 344:638-641. https://doi.org/10.1126/science. 1250498

Yang C, Xie F, Jiang Y, Li Z, Huang X, Li L (2018) Phytochrome A negatively regulates the shade avoidance response by increasing auxin/indole acidic acid protein stability. Dev Cell 44:29-41. https://doi.org/10.1016/j.devcel.2017.11.017

Yang D et al (2012) Plant hormone jasmonate prioritizes defense over growth by interfering with gibberellin signaling cascade. Proc Natl Acad Sci USA 109:1192-1200. https://doi.org/10. 1073/pnas.1201616109

Yang J, Lin R, Sullivan J, Hoecker U, Liu B, Xu L, Deng XW, Wang H (2005) Light regulates COP1-mediated degradation of HFR1, a transcription factor essential for light signaling in Arabidopsis. Plant Cell 17:804-821. https://doi.org/10.1105/ tpc.104.030205

Yao C, Finlayson SA (2015) Abscisic acid is a general negative regulator of Arabidopsis axillary bud growth. Plant Physiol 169:611-626. https://doi.org/10.1104/pp.15.00682

Yin R, Skvortsova MY, Loubéry S, Ulm R (2016) COP1 is required for UV-B-induced nuclear accumulation of the UVR8 photoreceptor. Proc Natl Acad Sci USA 113:E4415-4422. https:// doi.org/10.1073/pnas.1607074113

Zhang R, Yang C, Jiang Y, Li L (2019) A PIF7-CONSTANS-centered molecular regulatory network underlying shade-accelerated flowering. Mol Plant 12:1587-1597. https://doi.org/10. 1016/j.molp.2019.09.007

Zhao Y et al (2020) Creation two hyperactive variants of phytochrome B1 for attenuating shade avoidance syndrome in maize. J Integr Agric 19:2-14. https://doi.org/10.1016/ S2095-3119(20)63466-9

Zhou Y et al (2018) TCP transcription factors regulate shade avoidance via directly mediating the expression of both PHYTOCHROME INTERACTING FACTORS and auxin biosynthetic genes. Plant Physiol 176:1850-1861. https://doi.org/ 10.1104/pp.17.01566 